\title{
Reconstitution of the DTX3L-PARP9 complex reveals determinants for high affinity heterodimer formation and enzymatic function
}

Yashwanth Ashok ${ }^{1, \#, \&}$, Carlos Vela-Rodriguez ${ }^{1, \#}$, Chunsong Yang ${ }^{2}$, Heli I. Alanen ${ }^{1}$, Fan Liu ${ }^{3}$, Bryce M. Paschal ${ }^{2} \&$ Lari Lehtiö ${ }^{1, *}$

${ }^{1}$ Faculty of Biochemistry and Molecular Medicine \& Biocenter Oulu, University of Oulu, Finland.

${ }^{2}$ Department of Biochemistry and Molecular genetics, University of Virginia, PO Box 800577, Charlottesville, VA22908, USA

${ }^{3}$ Department of Structural Biology, Leibniz-Forschungsinstitut für Molekulare Pharmakologie (FMP), Berlin, Deutschland

\#These authors contributed equally

${ }^{\circledR}$ Current address: Dept. of Genome Sciences, University of Washington, Seattle, USA

*Corresponding author: Lari Lehtiö - lari.lehtio@oulu.fi 


\section{Abstract}

Ubiquitination and ADP-ribosylation are post-translational modifications that play major roles in pathways like DNA damage response and infection, making them attractive targets for therapeutic intervention. DTX3L, an E3 ubiquitin ligase, forms a heterodimer with PARP9. The complex has ubiquitin ligase activity and also ADP-ribosylates the C-terminus of ubiquitin on Gly $^{76}$. NAD+-dependent ADP-ribosylation of ubiquitin by DTX3L-PARP9 prevents ubiquitin from conjugating to protein substrates. By using individually produced proteins, we have studied the interaction between DTX3L and PARP9. We identify that the D3 domain (230 510) of DTX3L mediates interaction with PARP9 with nanomolar affinity and an apparent 1:1 stoichiometry. Our results also suggest the formation of a higher molecular weight oligomer mediated by the N-terminus of DTX3L (1-200). Furthermore, we show that ADP-ribosylation of ubiquitin at Gly ${ }^{76}$ is a reversible modification that can be removed by several macrodomaintype hydrolases. Our study provides a framework to understand how DTX3L-PARP9 mediates ADP-ribosylation and ubiquitination in an inter-regulatory manner. 


\section{Introduction}

Ubiquitination is a reversible post translational modification of proteins that results in the addition of a small protein called ubiquitin (Ub) to lysine residues of a target protein. Ubiquitination modifies protein properties such as stability, localization, and protein-protein interactions to name a few [1]. Conjugation of a single Ub onto substrate proteins is called monoubiquitination and this process can proceed further by the attachment of additional Ub units resulting in polyubiquitination and formation of Ub chains. Ubiquitination on substrate proteins is achieved by the consecutive action of three enzymes. Ub activating enzyme (E1) uses ATP to activate and transfer Ub to a Ub-conjugating enzyme (E2) that forms a thioester linkage with Ub (E2 Ub). Ubiquitin ligases (E3) recruit E2 Ub complex to transfer Ub onto substrate proteins.

Ubiquitination can be subject to crosstalk with other post-translational modifications such as phosphorylation [2]. There is also growing evidence of crosstalk between ubiquitination and ADP-ribosylation (reviewed in [3]). ADP-ribosylation is the attachment of ADP-ribose to proteins by enzymes that use $\mathrm{NAD}^{+}$as a substrate. ADP-ribose can be transferred as a single unit [mono-ADP-ribose (MAR)] or elongated to polymers of ADP-ribose [poly-ADP-ribose (PAR)]. In humans, majority of intra-cellular ADP-ribosylation is catalyzed by PARP enzymes of the Diphtheria toxin-like ARTD family [4]. PARylation has been shown to activate E3 ligases such as RNF146 and Trip21 [5,6] and recently MARylation of $\mathrm{Ub}$ on $\mathrm{Arg}^{42}$ and $\mathrm{Thr}^{66}$ by bacterial enzymes of SidE family and on Gly ${ }^{76}$ by human DTX3L-PARP9 complex was shown to regulate ubiquitination [7-10].

In an effort to identify critical genes that determine the outcome of treatable and fatal diffuse large B-cell lymphoma, a gene named $B A L$ (B aggressive lymphoma) was identified [11]. This gene was then re-named as PARP9 as the protein C-terminus was homologous to catalytic domain of PARPs [12]. In an attempt to define molecular processes mediated by PARP9 protein, a yeast two-hybrid screen with PARP9 as a bait identified DTX3L as an interacting protein [13]. DTX3L belongs to a family of E3 Ub ligases. Deltex family comprises five 
members; namely DTX1-4 and DTX3L, which have similar domains in the C-terminus of the protein sharing RING and the deltex C-terminal domain [14].

In addition to lymphomas, DTX3L-PARP9 complex has been shown to be overexpressed in tumours such as prostate and breast cancer [15-17]. DTX3L-PARP9 possibly supports tumour growth by repression of IRF-1, an important transcription factor that elicits proapoptotic responses. Overexpression of DTX3L or PARP9 repressed IRF-1 promoter and knockout of either DTX3L-PARP9 lead to increased transcription from IRF-1 promoter [18].

DTX3L-PARP9 was also shown to be involved in DNA damage response as deletion of either of the genes results in increased sensitivity to DNA damage. Knockdown resulted in decrease of non-homologous end joining (NHEJ) while overexpression of DTX3L-PARP9 promoted NHEJ [19]. Furthermore, DTX3L-PARP9 was recruited to sites of DNA damage with irradiated cells [16]. DTX3L-PARP9 was also shown to be involved in anti-viral response through regulation of IFN/STAT1 pathway [20].

Biochemically, DTX3L-PARP9 was shown earlier to mono ADP-ribosylate C-terminus of Ub on Gly ${ }^{76}[19]$. ADP-ribosylation at Gly ${ }^{76}$ is dependent on E1 and E2 processing of Ub and it was also shown that high $\mathrm{NAD}^{+}$concentration promotes $\mathrm{ADP}$-ribosylation of $\mathrm{Ub}$ and decreases Ub conjugation of substrates [19]. As an unmodified $\mathrm{Gly}^{76}$ is required for conjugating Ub onto substrates [21], ADP-ribosylation on this residue precludes ubiquitination.

Here we describe the characterization of individually produced DTX3L and PARP9 and demonstrate that the proteins form a high affinity complex. We show that the $\mathrm{N}$-terminal domain of DTX3L mediates oligomerization and that PARP9 is monomeric in solution. We also characterized the determinants of the complex formation and were able to show that the complex is mainly formed through interactions between the DTX3L D3 domain and the region of PARP9 preceding the PARP domain. Furthermore, we show that the reconstituted complex has both Ub ADP-ribosylation and ubiquitination activities. Using mass spectrometry we identified the auto-ubiquitination sites on DTX3L. We observed that the C-terminal part of 
DTX3L can ADP-ribosylate Ub in the absence of PARP9, but that the activity is enhanced when PARP9 is present. We also identify potential erasers for ADP-ribosylation on Gly ${ }^{76}$ in vitro using a panel of previously known ADP-ribosylation erasers.

\section{Materials and Methods:}

\section{Protein expression and purification}

Expression vectors pNH-TrxT (\#26106), pNIC-CH (\#26117), pFastBac1 His-MBP (\#30116) were procured from Addgene. pNIC28-MBP was constructed by replacement of TrxT with MBP [22]. Throughout the study, Uniprot IDs corresponding to DTX3L (\#Q8TDB6-1) and PARP9 (\#Q8IXQ6-1) were used. All constructs were verified by dideoxy sequencing. Details of expression constructs are provided in Table $\mathbf{S 1 .}$

Expression constructs were transformed into BL21 (DE3) and selected on appropriate antibiotic selection plates. Overnight culture with $50 \mu \mathrm{g} / \mathrm{ml}$ of kanamycin were grown at $37^{\circ} \mathrm{C}$. Terrific Broth-autoinduction media (Formedium, UK) supplemented with $8 \mathrm{~g} / \mathrm{l}$ glycerol was used for protein expression. Briefly, when the bacterial culture grown at $37^{\circ} \mathrm{C}$ reached 1 O.D, the incubation temperature was reduced to $18^{\circ} \mathrm{C}$ overnight. Cultures were harvested by centrifugation and frozen with lysis buffer until required.

For protein expression in insect cells, recombinant bacmids were transfected into Sf21 cells using Fugene6 (Promega E2693). Supernatant containing viruses $\left(\mathrm{V}_{0}\right)$ was harvested after seven days. These viruses were amplified once more to increase the virus titre $\left(\mathrm{V}_{1}\right)$. Typically, $1 \times 10^{6}$ cells were used for protein expression using an appropriate volume of $\mathrm{V}_{1}$ virus that was predetermined to induce growth arrest in small-scale experiments. Cell pellets were harvested 72 hours after growth arrest and frozen at $-20^{\circ} \mathrm{C}$ with lysis buffer before use.

Cell pellets resuspended in lysis buffer $(50 \mathrm{mM}$ Hepes $\mathrm{pH} 7.4,0.5 \mathrm{M} \mathrm{NaCl}, 10 \%$ glycerol, $0.5 \mathrm{mM}$ TCEP and $10 \mathrm{mM}$ Imidazole) were sonicated and centrifuged at $16,000 \mathrm{rpm}$ to 
separate soluble material from cellular debris. Filtered supernatant was then loaded to preequilibrated HiTrap ${ }^{\mathrm{TM}}$ IMAC columns (Cytiva Biosciences). Columns were washed with lysis buffer, followed by wash buffer $(50 \mathrm{mM}$ Hepes $\mathrm{pH} 7.4,0.5 \mathrm{M} \mathrm{NaCl}, 10 \%$ glycerol, $0.5 \mathrm{mM}$ TCEP and $25 \mathrm{mM}$ imidazole) and then eluted with elution buffer (50 mM Hepes $\mathrm{pH} 7.4,0.35 \mathrm{M}$ $\mathrm{NaCl}, 10 \%$ glycerol, $0.5 \mathrm{mM}$ TCEP and $350 \mathrm{mM}$ Imidazole). For constructs with MBP tag, IMAC elution was loaded into MBP-Trap columns, washed with SEC buffer (30 mM Hepes pH 7.5, $0.35 \mathrm{M} \mathrm{NaCl}, 10 \%$ glycerol, $0.5 \mathrm{mM} \mathrm{TCEP)}$ ) and eluted in same buffer with $10 \mathrm{mM}$ maltose. Pooled fractions from MBP column or from other constructs without MBP tag from IMAC were digested with TEV protease (in-house preparation) [23] with 1:30 (TEV:recombinant protein) molar ratio for 1-2 days followed by reverse IMAC purification to remove TEV and cleaved tags. Proteins collected in the flowthrough were pooled and run in SEC, verified by SDS-PAGE and flash frozen and stored at $-70^{\circ} \mathrm{C}$. Protein identity was verified by MALDI-TOF analysis.

Co-expressed DTX3L-PARP9 complex was produced as previously reported [19].

\section{aSEC studies}

Superdex 200 10/30 increase equilibrated with running buffer (30 mM Hepes pH 7.5, 150 mM $\mathrm{NaCl}, 5 \%$ glycerol, $0.5 \mathrm{mM}$ TCEP) at a flowrate of $0.3 \mathrm{ml} / \mathrm{min}$ was used. BioRad gel filtration calibration kit was used as a standard. Fluorescent labelling was done using DyLight 488 (Thermo) at $9.8 \mathrm{mM}$. The dye was added to PARP9 FL and PARP9 M1 in an equimolar ratio and incubated for an hour at room temperature kept from the light. Excess dye was removed with a Zeba ${ }^{\mathrm{TM}} 7 \mathrm{~K}$ MWCO spin desalting column (ThermoFisher) equilibrated with running buffer.

\section{Ubiquitination assays}

Ubiquitination reactions for DTX3L constructs were prepared in $50 \mu \mathrm{L}$ volume by mixing (Ube1, E1) $0.4 \mu \mathrm{M}$, (Ubc5Ha, E2) $2 \mu \mathrm{M}$, DTX3L $(0.67 \mu \mathrm{M})$ and Ub $(45 \mu \mathrm{M})$. Tris buffer $(1 \mathrm{M}$, $\mathrm{pH} 7.5)$ containing ATP $(40 \mathrm{mM}), \mathrm{MgCl}_{2}(100 \mathrm{mM})$ and DTT $(40 \mathrm{mM})$ was added in a $1: 20$ buffer to reaction volume ratio to initiate ubiquitination. Upon ATP addition, the reaction was 
incubated at room temperature for up to $2 \mathrm{~h}$. The reaction was quenched by adding $2 \mathrm{x}$ Laemmli buffer at times 0, 15, 30, 60 and $120 \mathrm{~min}$ and analyzed using SDS-PAGE and coomassie staining. WT ubiquitin was produced in-house while single lysine ubiquitin and K0 ubiquitin were obtained from LifeSensors (Cat. \# SI210).

\section{Identification of Ubiquitination sites}

Ubiquitination reactions with DTX3L FL were conducted and resolved with SDS-PAGE. Bands corresponding to modified and unmodified proteins were cut from the gel and washed with $190 \mathrm{~mL} \mathrm{40 \%} \mathrm{acetonitrile} \mathrm{(ACN)} 50 \mathrm{mM}$ ABic buffer until the gel piece was colourless. Then the sample was incubated at room temperature for 60 min with $100 \mu \mathrm{L}$ of $40 \%$ ACN $50 \mathrm{mM}$ ABic buffer and $2 \mu \mathrm{L} 1 \mathrm{M}$ DTT. After adding $4.2 \mu \mathrm{L}$ of iodoacetamide (IAA), the sample was incubated for 30 more minutes. Following the incubation, gel pieces were washed with $190 \mu \mathrm{L}$ 40\% acetonitrile (ACN) $50 \mathrm{mM} \mathrm{ABic} \mathrm{buffer} \mathrm{and} \mathrm{immediately} \mathrm{after} \mathrm{with} 190 \mu \mathrm{L}$ of sterile water. Liquid was removed from the gel and afterwards $5 \mu \mathrm{L}$ of trypsin (1/50 T7575, Sigma Aldrich) were added incubating the gel overnight at room temperature.

Trypsin-digested proteins were analyzed by LCMS analysis using an Easy-nLC 1000 system (ThermoFisher Scientific) coupled to a Fusion Lumos Tribrid mass spectrometer (ThermoFisher Scientific). Peptides were trapped on a Symmetry C18 $0.18 \times 20 \mathrm{mM}$ trap column (Waters) and separated on a Waters M/Z Peptide BEH C18 $130 \AA 1.7 \mu \mathrm{m}$ $0.075 \times 150 \mathrm{~mm}$ column using a gradient from $97 \% \mathrm{~A}(0.1 \%$ formic acid $)$ to $35 \% \mathrm{~B}(0.1 \%$ formic acid in $\mathrm{ACN}$ ) over $60 \mathrm{~min}$ at a flow rate of $0.3 \mu \mathrm{l} / \mathrm{min}$. The instrument was operated in $3 \mathrm{sec}$ cycles where the MS spectra were recorded with the orbitrap analyzer at resolution of 120000 allowing the collection of up to $4 \mathrm{e}^{5}$ ions for maximal $100 \mathrm{msec}$ before switching to MS/MS mode. Multicharged ions (threshold $\left.2.5 \mathrm{e}^{4}\right)$ were fragmented by HCD (30\% collision energy) using quadrupole isolation with $1.6 \mathrm{Da}$ width and $15 \mathrm{sec}$ dynamic exclusion. Up to $5 \mathrm{e}^{4}$ fragment ions were collected for max $100 \mathrm{msec}$ and analyzed in the orbitrap analyzer at a resolution of 15000 . lons between 1000 and 25000 in intensity were fragmented in the same 
way but MS/MS scans were recorded in the ion trap (rapid mode) aiming at higher sensitivity (threshold $1 \mathrm{e}^{4}$, max $300 \mathrm{msec}$ ).

Raw data were and analyzed with Proteome Discoverer 2.2 (ThermoFisher Scientific) using SEQUEST as search engine. MS/MS spectra recorded in the ion trap were processed with a 0.6 Da mass tolerance and data recorded with the orbitrap with a 0.02 Da tolerance. Raw data were recalibrated with the SWISS-PROT human database (9605, v2017-07-05) and after spectrum selection searched against the same database with the following settings: precursor mass tolerance $10 \mathrm{ppm}$, trypsin cleavage with up to 2 missed cleavages, carbamidomethyl on Cys, oxidation on Met, deamidation on Gln and Asn, protein N-terminus acetylated, and GG adduct on Lys as optional modifications.

Ubiquitin remnant peptides (GG peptides attached to lysine) were identified by searching for $+114.042928 \mathrm{Da}$ in lysine residues. Only peptides that showed $100 \%$ abundance in ubiquitinated sample when compared to the control sample were taken as ubiquitinated peptides. As trypsin cannot cleave at Ubiquitin modified lysines, peptides with C-terminal KGG were excluded.

\section{ADP-ribosylation assays}

The assays were performed in $20 \mu \mathrm{l}$ of volume containing $50 \mathrm{mM}$ Tris- $\mathrm{HCl}(\mathrm{pH} 7.5), 50 \mathrm{mM}$ $\mathrm{NaCl}, 5 \mathrm{mM} \mathrm{MgCl}$, $1 \mathrm{mM}$ DTT, $0.5 \mathrm{mM} \mathrm{ATP,} 0.1 \mathrm{mg} / \mathrm{ml}$ His6-T7-ubiquitin, $12.5 \mathrm{mM}$ biotin$\mathrm{NAD}^{+},\left(-/+\right.$unlabeled $\left.\beta-\mathrm{NAD}^{+}\right), 10 \mathrm{mg} / \mathrm{ml}$ each of Ube1 (E1) and $\mathrm{UbcH8}(\mathrm{E} 2)$, and $0.25 \mathrm{mg}$ DTX3L alone, 0.05 mg His6-DTX3L(557-740), 0.5 mg PARP9 alone, 0.25 mg DTX3L + 0.5 mg PARP9 mixture (pre-incubated at $4^{\circ} \mathrm{C}$ for $>60 \mathrm{~min}$ to form complex), $0.2 \mathrm{mg}$ recombinant DTX3L-(His6)PARP9 purified from bacteria, with or without $2 \mathrm{mg}$ Histone H2A. The reactions were incubated at $30^{\circ} \mathrm{C}$ for $30 \mathrm{~min}$, quenched by adding $2 \times$ Laemmli buffer, separated in SDSPAGE, and followed with detection by Neutravidin-DyLight-800 (Pierce 22853) for biotin-ADP ribosylated Ub and anti-Ub-H2A (Cell signaling Technology \#8240) for H2A ubiquitylation.

\section{Hydrolysis assays}


His6-T7-Ub was ADP-ribosylated in the presence of $1 \mathrm{mM}$ unlabeled $\beta$-NAD+. The unreacted $\beta-\mathrm{NAD}^{+}$was removed with Zeba Spin Desalting column (Thermo Scientific \#89892). The hydrolyses of ADP-ribose (ADPr)-Ub were performed in $20 \mathrm{mM}$ Tris- $\mathrm{HCl}(\mathrm{pH} 7.5), 50 \mathrm{mM}$ $\mathrm{NaCl}, 5 \mathrm{mM} \mathrm{MgCl} 2,2 \mathrm{mM}$ DTT, $0.2 \mathrm{mg} / \mathrm{ml} \mathrm{BSA}$ and $0.3 \mathrm{mM}$ hydrolase at $37^{\circ} \mathrm{C}$ for $60 \mathrm{~min}$. ARP (Biotin-containing reagent, Cayman Chemical \# 10009350) modification of the remaining ADPr-Ub were carried out in the presence of $1 \mathrm{mM} \mathrm{ARP} \mathrm{in} 0.5 \mathrm{mM}$ acetic acid at room temperature for 60 min [19]. The reactions were stopped with 2x Laemmli buffer mixed with neutralizing $\mathrm{NaOH}$, separated by SDS-PAGE, and quantified by Neutravidin-DyLight-800 detection.

\section{Cross-linking and XL-MS}

Cross-linking reactions were carried out at room temperature in $30 \mathrm{mM} \mathrm{HEPES} \mathrm{buffer,} \mathrm{pH}$ 7.5, with $350 \mathrm{mM} \mathrm{NaCl}, 10 \%(\mathrm{v} / \mathrm{v})$ glycerol, $0.5 \mathrm{mM}$ TCEP. PARP9 FL was mixed in equimolar ratios with DTX3L D3 and with DTX3L D3RD, at $15 \mu \mathrm{M}$ and $8.6 \mu \mathrm{M}$ respectively in $100 \mu \mathrm{L}$. To initiate reaction, freshly prepared $\mathrm{BS}^{3}$ (Thermo Scientific, \#21580, Lot\#OJ192037) was added to a final concentration of $500 \mu \mathrm{M}$ to each reaction. $\mathrm{BS}^{3}$ was prepared by dissolving $2 \mathrm{mg}$ of $\mathrm{BS}^{3}$ powder in $277 \mu \mathrm{L}$ of distilled water to make a $12.5 \mathrm{mM}$ working stock solution.

After incubation at appropriate times, aliquots were quenched by addition of $1 \mathrm{M}$ Tris- $\mathrm{HCl}$ buffer, $\mathrm{pH} 8.5$ (0.47 $\mathrm{mM}$ final concentration) to a $10 \mu \mathrm{L}$ aliquot taken from the reaction. Samples were incubated for $20 \mathrm{~min}$ at room temperature and then analyzed by SDS PAGE. Bands of the expected molecular weight for both complexes (PARP9 FL-DTX3L D3 and PARP9 FL-DTX3L D3RD), were recovered from the gel for cross-linking mass spectrometry analyses.

Cross-linking of D1, D2 and D1D2 was done in a similar manner as the cross-linked complexes. Protein concentration used for these reactions was $0.5 \mathrm{mg} / \mathrm{mL}$ and quenching of the reaction was done after $10,15,30,45$, and $60 \mathrm{~min}$. Samples were resolved using SDSPAGE and PageBlue staining (Thermo Scientific). 
Cross-linked PARP9-D3 and PARP9-D3RD were loaded on SDS-PAGE and subjected to ingel digestion. Gel bands were reduced with $5 \mathrm{mM}$ DTT at $56^{\circ} \mathrm{C}$ for $30 \mathrm{~min}$ and alkylated with $40 \mathrm{mM}$ chloroacetamide at room temperature for $30 \mathrm{~min}$ in the dark. Protein digestion was carried out using trypsin at an enzyme-to-protein ratio of $1: 20(\mathrm{w} / \mathrm{w})$ at $37^{\circ} \mathrm{C}$ overnight.

Cross-linked DTX3L-PARP9 were digested in-solution by adding urea (6 M final concentration). The samples were reduced with $5 \mathrm{mM}$ DTT at $37^{\circ} \mathrm{C}$ for $60 \mathrm{~min}$ and alkylated with $40 \mathrm{mM}$ chloroacetamide at room temperature for $30 \mathrm{~min}$ in the dark. Protein digestion was carried out using Lys $\mathrm{C}$ at an enzyme-to-protein ratio of $1: 75(\mathrm{w} / \mathrm{w})$ at $37^{\circ} \mathrm{C}$ for $4 \mathrm{~h}$. After diluting to $2 \mathrm{M}$ urea, the digestion was continued with trypsin at an enzyme-to-protein ratio of 1:100 (w/w) at $37^{\circ} \mathrm{C}$ overnight. The samples were cleaned up with $\mathrm{C} 18$ stageTip.

LC/MS analysis was performed using an UltiMate 3000 RSLC nano LC system coupled online to an Orbitrap Fusion mass spectrometer (Thermo Fisher Scientific). Reversed-phase separation was performed using a $50 \mathrm{~cm}$ analytical column (in-house packed with Poroshell 120 EC-C18, $2.7 \mu \mathrm{m}$, Agilent Technologies) with a $120 \mathrm{~min}$ gradient. Data analysis was performed using pLink 2.3.9 with the following parameters: tryptic in silico digestion with minimum peptide length=6; maximal peptide length $=60$ and missed cleavages $=3$; fix modification: Cys carbamidomethyl=57.021 Da; variable modification: Met oxidation=15.995 Da; $\mathrm{BS}^{3}$ cross-linker=138,068 Da. Crosslinks that appeared at least in two of the four measurements were taken for further analysis. XL-MS figures were generated using xiNET [24].

\section{Biolayer interferometry (BLI)}

Determination of the affinity parameters was performed using the Octet RED384 (Forté Bio). All binding studies were performed in freshly prepared $30 \mathrm{mM}$ HEPES buffer, $\mathrm{pH} 7.5$, containing $150 \mathrm{mM} \mathrm{NaCl}, 5 \%(\mathrm{v} / \mathrm{v})$ glycerol, $0.5 \mathrm{mM}$ TCEP, $10 \mathrm{mg} / \mathrm{ml} \mathrm{BSA}$ and $0.05 \%(\mathrm{v} / \mathrm{v})$ Tween 20. The buffer was filtered with a $0.22 \mu \mathrm{m}$ Minisart@ PES syringe filter (Sartorius).

PARP9 FL and heat-inactivated BSA were biotinylated with $1 \mathrm{mM}$ NHS PEG biotin. 
Biotinylation reaction was incubated for $30 \mathrm{~min}$ at room temperature and the excess biotin was removed with a Zeba ${ }^{\mathrm{TM}} 7 \mathrm{k}$ MWCO desalting column (Thermo Scientific).

The affinity measurements were carried out at $30^{\circ} \mathrm{C}$ using a working volume of $200 \mu \mathrm{L}$ in black Greiner 96-well flat-bottom plates and 1000 rpm agitation. Eight streptavidin SA Dip and read TM biosensors (FortéBio) were loaded with biotinylated $20 \mu \mathrm{g} / \mathrm{mL}$ BSA as a reference for nonspecific interactions. Eight streptavidin SA sensors were loaded with $10 \mu \mathrm{g} / \mathrm{mL}$ biotinylated PARP9 FL. Binding affinity was tested with DTX3L D3RD and DTX3L FL at 320, 160, 80, 20, $5,2.5,0.625$ and $0 \mathrm{nM}$ diluted in the working buffer. The association step was kept for $30 \mathrm{~min}$ to ensure signal saturation.

FortéBio Data Analysis HT 11.0 software was used for data analysis. After subtracting the signal from the reference sensors from the signal of the sensors loaded with PARP9 FL, the binding sensogram was aligned at the beginning of the association step. The sensograms were fit using a global model assuming a 1:1 interaction model in steady state.

\section{SAXS data collection and analysis}

DTX3L FL (3.9 mg/mL) and D1D2 $(17 \mathrm{mg} / \mathrm{mL})$ were analyzed by SEC SAXS at Diamond Light Source B21 beamline (Oxfordshire, United Kingdom). Samples were run by injecting $60 \mu \mathrm{L}$ to a Superose 6 increase $3.2 / 300$ column at a flowrate of $0.6 \mathrm{~mL} / \mathrm{min}$ with $30 \mathrm{mM}$ Hepes $(\mathrm{pH}$ 7.5), $350 \mathrm{mM} \mathrm{NaCl}, 5 \%$ glycerol, $0.5 \mathrm{mM}$ TCEP. The column was connected to the SAXS system on the B21 beamline. Based on the Guinier Rg, matching frames from the main peak were averaged. Data processing was done using ScÅtter [25] to determine the maximum distance (Dmax), volume and Rg. Molecular weight was determined with Primus (Atsas suite 3.0.3) using the MW and $\mathrm{I}(0)$ of BSA [26]. Additionally, MW was also calculated with the intensity file with the SAXSMoW server [27]. Data for DTX3L FL could not be processed due to the lack of uniformity in the data recorded.

\section{Results}




\section{PARP9 is a monomer in solution}

Computational predictions on human PARP9 indicate three structural domains in PARP9 (Fig. 1A). In order to characterize full-length PARP9, we expressed and purified PARP9 from insect cells. Several truncations were also produced to study individual domains (Fig. 1A and Table S1). Analytical size exclusion chromatography (aSEC) studies show that full-length PARP9 elutes at a volume corresponding to that of a monomer (Fig. 1B). Further studies with multi angle light scattering (MALS) also confirmed that PARP9 exists as a monomer with an observed molecular weight of $94 \mathrm{kDa}$ with a theoretical molecular weight of $96 \mathrm{kDa}$ (Fig. 1C).
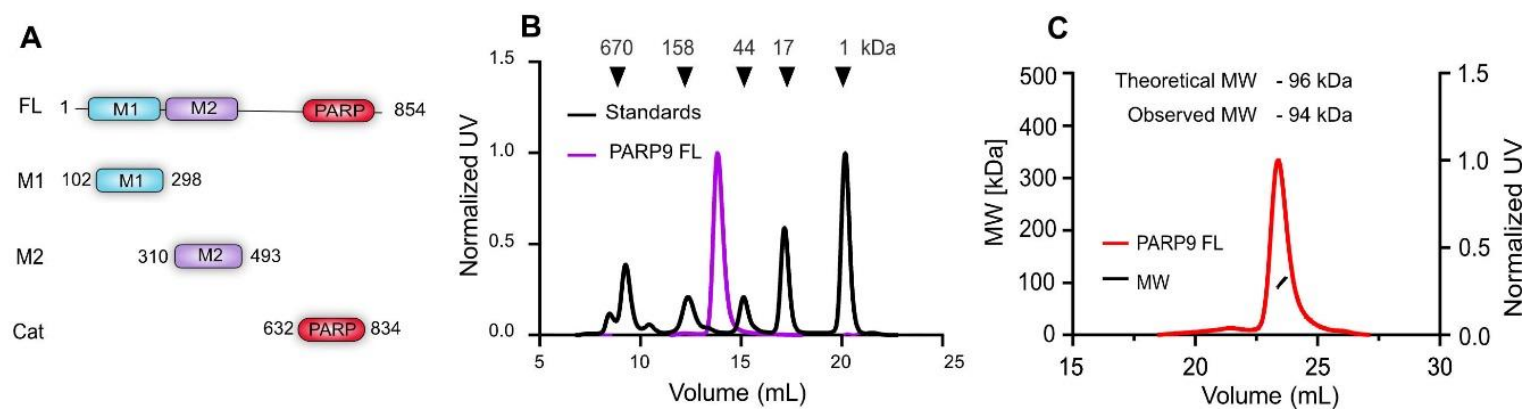

Fig 1. PARP9 domains and solution behaviour. A) Domain organization of PARP9 and constructs used in the studies. B) aSEC analysis of FL PARP9. Protein standards eluting at expected volume are indicated by black arrows and their corresponding molecular weight. C) SEC-MALS analysis of full-length of purified PARP9.

\section{D2 domain of DTX3L is the major determinant of oligomerization}

Full-length DTX3L and several truncations were produced from insect cells and $E$. coli respectively (Fig 2A and Table S1). Interestingly, full-length DTX3L appeared to be oligomeric based on the protein eluting at a volume corresponding to molecular weight higher than 158 kDa with a theoretical mass of $84 \mathrm{kDa}$ in aSEC. (Fig. 2B). To identify the domain responsible for DTX3L oligomerization, several deletion constructs were produced. We observed that the $\mathrm{N}$-terminal domains spanning regions D1-D2 were oligomeric with an elution volume close to $158 \mathrm{kDa}$, contrary to an expected value of $23 \mathrm{kDa}$ (Fig. 2B). In subsequent experiments with 
smaller D1 and D2 constructs, D2 domain appeared oligomeric with an elution volume that corresponds to proteins higher than $44 \mathrm{kDa}$ as opposed to a theoretical $11 \mathrm{kDa}$ (Fig. 2B). The behaviour of D1 domain seemed monomeric as its elution profile coincided with a theoretical value of $11 \mathrm{kDa}$ (Fig. 2B). Cross-linking experiments with $\mathrm{BS}^{3}$ showed that D1-D2 forms an oligomer of about $125 \mathrm{kDa}$, a value that lies between the expect MW of a pentamer (113 kDa) and hexamer (136 kDa) (Fig. 2C). D1 domain alone showed a small amount of dimer formation and D2 domain showed bands corresponding to a tetramer (Fig. 2D,E). To further characterize DTX3L oligomer formation, we used small angle X-ray scattering (SAXS) with purified D1-D2 domains and full length DTX3L (data not shown for latter). We observed that the elution peak for D1-D2 domains was not entirely symmetric suggesting the presence of multiple species (Fig. S1A). On the other hand, intensity measurements for FL DTX3L indicate a polydisperse sample, which prevented the analysis of the sample. The relatively low uniformity observed agrees with the cross-linking data and the calculated MWs based on two different methods (114 kDa from PRIMUS and $121 \mathrm{kDa}$ from SAXSMoW) fit well with the calculated MW of a pentamer but does not exclude possibility of a hexamer (Fig. S1).

A

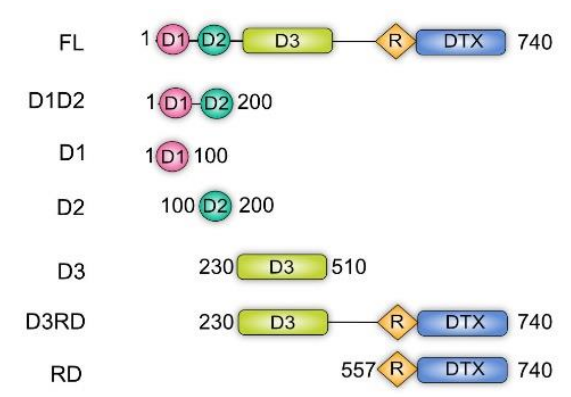

B

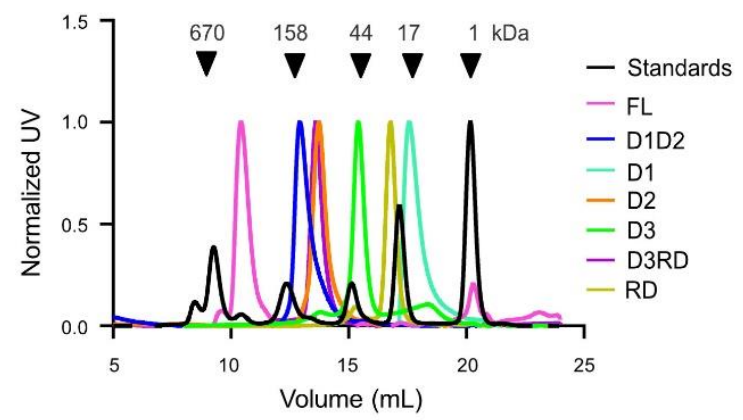

C

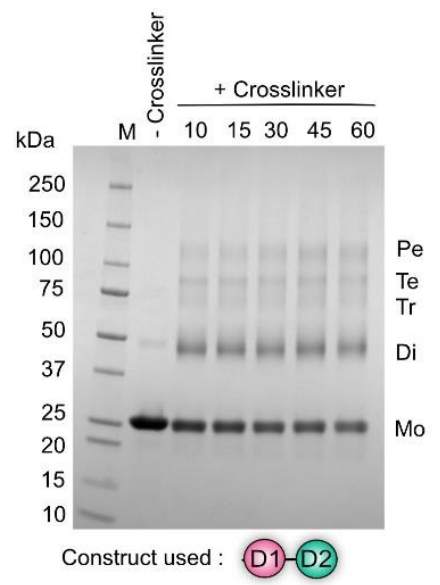

D

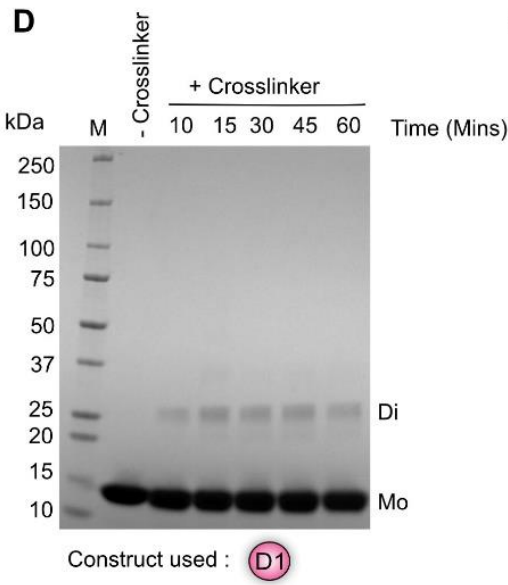

E

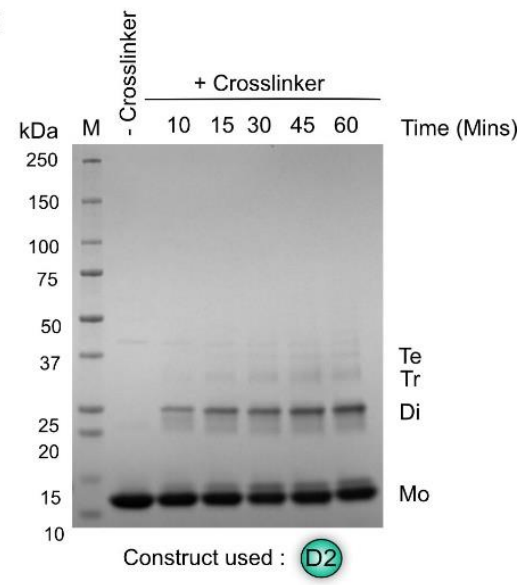


Fig 2. DTX3L D2 domain is the major mediator of oligomerization A) Domain organization of DTX3L and constructs used for experiments. B) aSEC of purified DTX3L proteins. Elution volumes of gel filtration standards are indicated by black arrows and their corresponding molecular weights. C, D, E) SDS-PAGE showing crosslinking analysis of purified proteins with $\mathrm{BS}^{3}$ for D1-D2, D1 and D2 constructs, respectively.(Abbreviations on the sides of the gel (Mo monomer, Di- dimer, Tr- trimer, Te- tetramer, Pe- pentamer).

\section{D3 domain is sufficient for interaction with PARP9}

With purified proteins in hand, we then analyzed complex formation between full-length PARP9 and various DTX3L constructs. We used size exclusion chromatography coupled with fluorescently-labeled PARP9, which enabled us to distinguish DTX3L-PARP9 complexes from DTX3L oligomers. As FL DTX3L elutes at an early volume corresponding to a high molecular weight protein, complex formation with FL PARP9 does not significantly change the elution volume. Therefore, we labelled PARP9 with a fluorophore to aid the visualization of complex formation in size exclusion chromatography. We confirmed that chemical labelling with a fluorophore did not alter solution behavior of PARP9 (Fig. S2). Labeled PARP9 was then mixed with full-length DTX3L and analyzed using size exclusion chromatography (Fig. 3A). Fluorophore labelled PARP9 shifts elution volume when incubated with full-length DTX3L indicating complex formation. Therefore, full-length PARP9 readily formed complexes with fulllength DTX3L. Subsequent experiments with DTX3L truncations revealed that D3RD (D3-RDTX) and D3 domain formed complexes with full-length PARP9 (Fig. 3B,C). N-terminal D1D2 domains and RD domains of DTX3L were dispensable for complex formation. Similarly, the catalytic domain and M1 of PARP9 were unable to form complexes in fluorescence size exclusion chromatography (Fig. S3). 
A

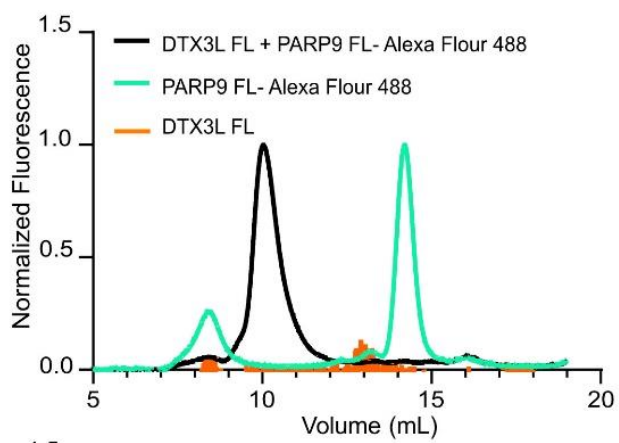

C
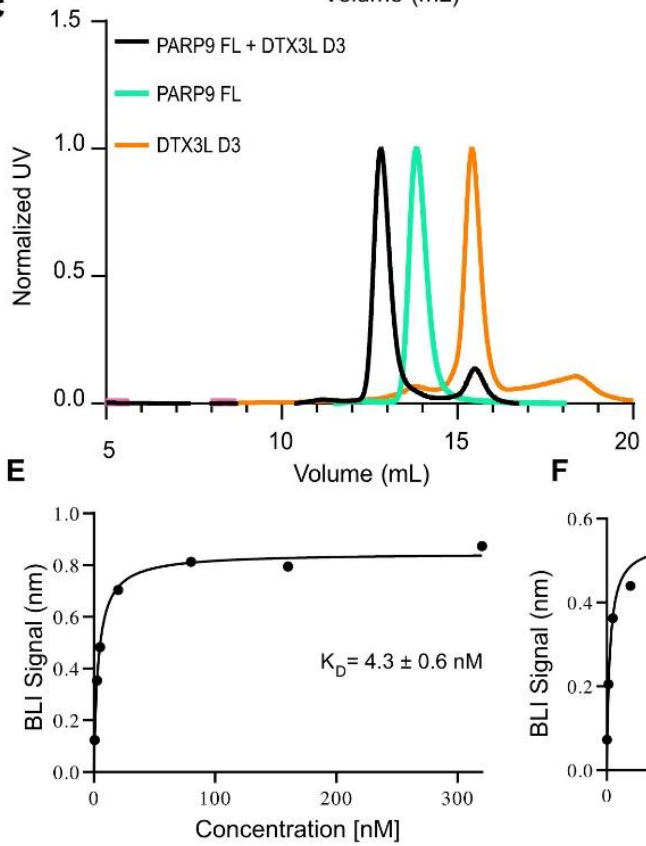

B

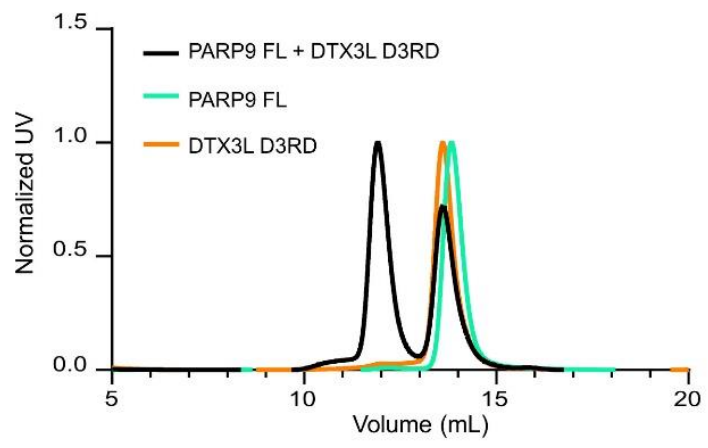

D
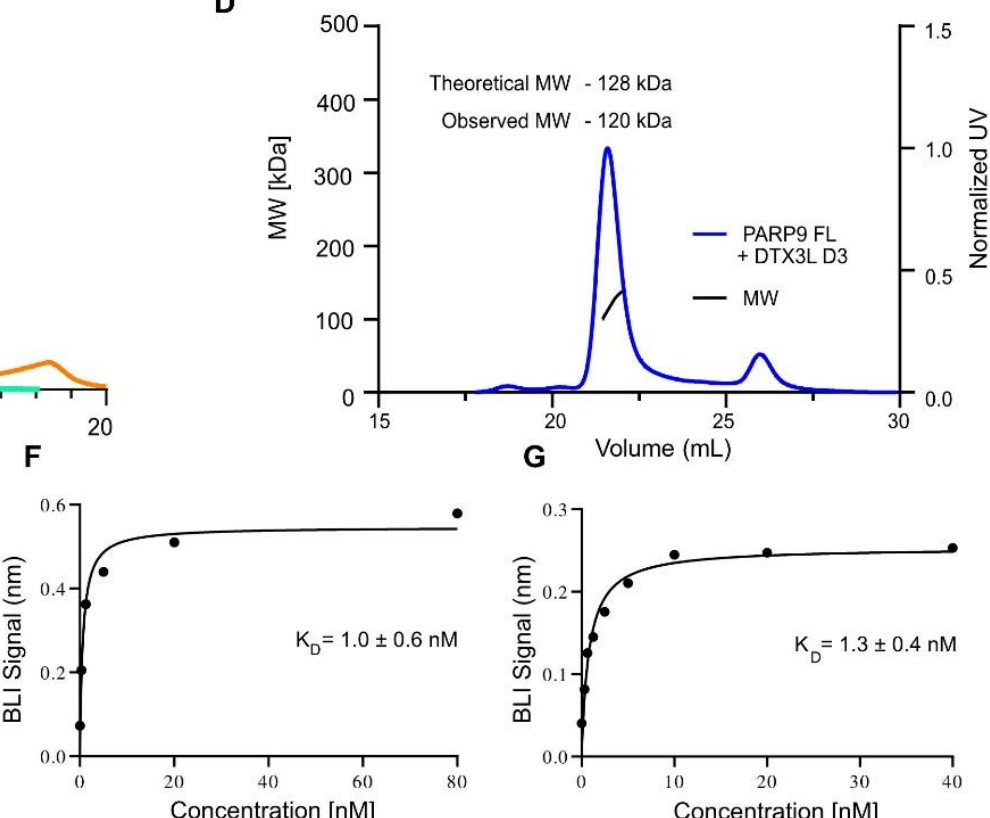

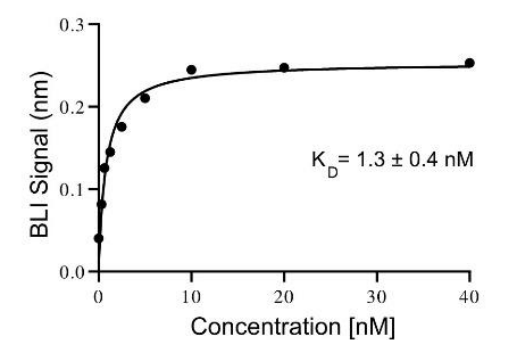

Fig 3. D3 domain of DTX3L is responsible for complex formation. A) Fluorescence size exclusion chromatography of full-length DTX3L and fluorophore labelled PARP9. B) SEC showing complex formation with full-length PARP9 and DTX3L D3RD domains. C) SEC showing complex formation with full-length PARP9 and DTX3L D3 domain. D) SEC-MALS analysis showing 1:1 stoichiometry of full-length PARP9 and DTX3L D3 domain. E) Bio-layer interferometry (BLI) quantitation of protein-protein interaction between PARP9 full-length and full-length DTX3L. F) Bio-layer interferometry (BLI) quantitation of protein-protein interaction between PARP9 full-length and DTX3L D3RD. G) Bio-layer interferometry (BLI) quantitation of protein-protein interaction between PARP9 full-length and DTX3L D3 domain. $K_{D}$ values are reported as mean $\pm S D(n=3)$.

The complex of the DTX3L-D3 and PARP9 had an apparent 1:1 stoichiometry based on SECMALS (Fig. 3D and Fig. S4) and we then measured the affinity of complex formation of FL 
PARP9 with FL DTX3L, D3RD and D3. In all cases the biolayer interferometry showed single digit nanomolar affinities with $\mathrm{K}_{\mathrm{DS}}$ of 1.0 to $4.3 \mathrm{nM}$ (Fig. 3E-G and Fig. S5). This is in line with the earlier observation that the complex can be extracted from the cells directly [19].

\section{XL-MS identifies interaction interfaces of DTX3L and PARP9}

In order to get further insight into the complex formation we turned into cross-linking mass spectrometry (XL-MS), a technique where proteins or protein complexes are treated with bifunctional cross-linkers linking physically proximal regions of the protein and analyzing linked peptides after proteolysis [28,29]. We performed XL-MS with full-length PARP9 and three different constructs of DTX3L to identify both inter- and intra-molecular contacts at peptide level resolution. Despite evidence of D2 domain mediating oligomerization, we observed no cross-links between D2 domains in full-length context (Fig. 4A). This could be interpreted as lack of proximal lysines in the regions that oligomerize. Two cross-linked sites in DTX3L, K408 and K728 were cross-linked to themselves (i.e., a peptide containing K408 was cross-linked to K408 on another peptide), suggesting that these regions at least in context of full-length DTX3L come in proximity with each other, but this is the only direct evidence from cross-linking to an oligomer formation.
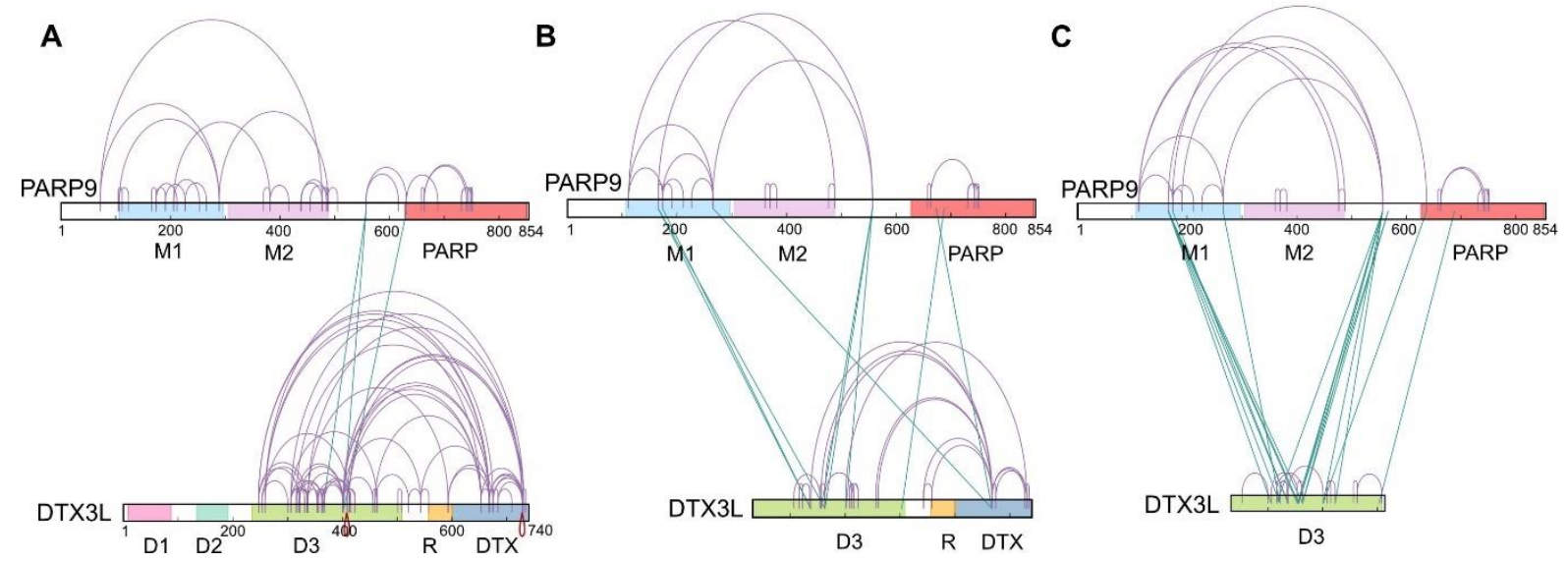

Fig 4. XL-MS analysis of PARP9-DTX3L complexes reveals interaction surfaces. A) Intraprotein links are shown as purple arcs. Inter-protein links are shown as cyan lines between PARP9 and DTX3L. A) Crosslink maps for full-length PARP9 and full-length DTX3L. B) 
Crosslink maps of full-length PARP9 and DTX3L D3RD domains. C) Crosslink maps of fulllength PARP9 and DTX3L D3 domain. Intra-protein crosslinks are shown as purple lines. Interprotein crosslinks are depicted as green lines. Symmetrical peptide cross-links (e.g., K408 cross-linked to K408 on another peptide) are shown in red lines.

For full-length proteins we observed 70 intra-protein cross-links DTX3L and 30 intra-protein cross-links in PARP9. Three inter-protein peptide cross-links between PARP9 and DTX3L were seen (Fig. 4A). These cross-links were observed between the D3 domain of DTX3L and the region located between M2 and PARP domains of PARP9. On the other hand, 49 high confidence intra- and inter-protein cross-links were observed between PARP9 and D3RD domains of DTX3L (Fig. 4B). Of the 49 cross-links, 18 were PARP9 intra-protein cross-links, 22 DTX3L intra-protein cross-links and 9 inter-protein cross-links. With a shorter D3 domain, 21 intra-protein cross-links were seen in PARP9, 12 within D3 domain and 18 inter-protein cross-links (Fig. 4C). Macrodomain M1 of PARP9 does not cross-link in the context of fulllength DTX3L but steadily increases cross-linked peptides with shorter DTX3L constructs (four for D3RD and seven for D3 domain) (Fig. 4A-C). These results suggest that longer constructs restrain mobility of the domains with respect to each other. Two inter-protein cross-links were common for all three DTX3L constructs: PARP9 K557 is a hotspot for interaction with DTX3L D3 domain residues K401 and K363. Overall cross-linking patterns indicate that PARP9 and DTX3L form a compact structure (Fig. 4A-C). We used available crystal structures of PARP9 and DTX3L domains to validate the used cross-linking method (Fig. S6).

\section{DTX3L undergoes multi-domain auto-ubiqutination}

We then used the purified DTX3L constructs to study auto-ubiquitination. Ubiquitination results in an increase of the molecular weight on proteins due to the covalent attachment of $\mathrm{Ub}$. We show, using time course analysis, that purified DTX3L forms smears consistent with the addition of multiple Ubs (Fig. 5A). All the constructs that contained the RD region (R-DTX) were active in the ubiquitination assay when E1, E2 and ubiquitin were supplied together with 
ATP (Fig. 5B). We then used mass spectrometry (MS) to map ubiquitination sites in DTX3L and were able to identify 34 auto-ubiquitination sites in multiple domains of DTX3L, with the RING domain being the only exception containing no modification sites (Fig. 5C). While the extent to which one or multiple ubiquitination sites in DTX3L are utilized in cells is an open question. It is probable that the protein concentration and DTX3L self-association promotes its modification in vitro. Ub has 7 lysine residues all of which can be ubiquitinated along with $\mathrm{N}$-terminal methionine creating linear Ub chains and using MS analysis we identified that the poly-Ub chains produced by DTX3L are linked through K6, K11, K48 and K63. These linkage types indicate the potential for DTX3L to modify proteins in the contexts of proteasomal degradation and the DNA damage response (DDR) in line with previous studies [30-33] (Fig. 5D). The ubiquitin reaction carried out with Ub with single lysine mutations and Ub without any lysine (KO) revealed that in all cases DTX3L gets auto-ubiquitinated consistent with multiple possible linkers and/or multiple modifications sites identified within DTX3L (Fig. 5E).

A

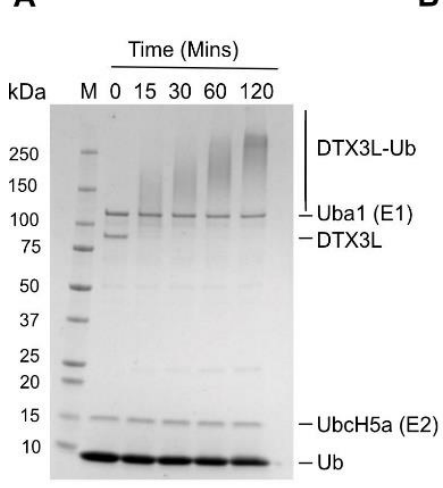

C

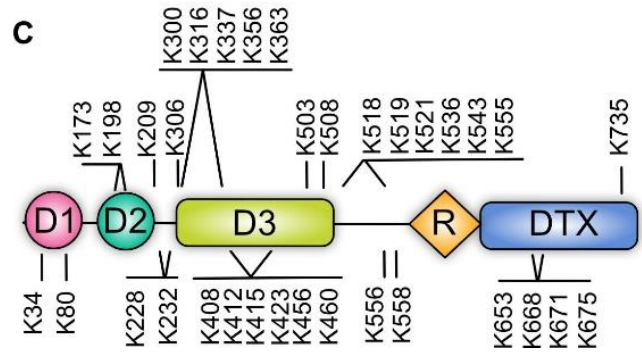

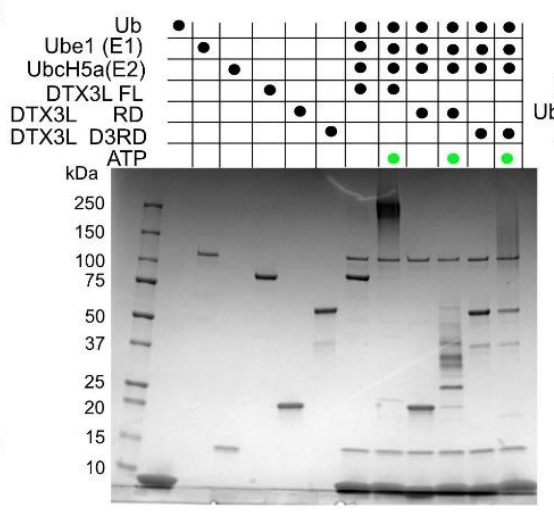

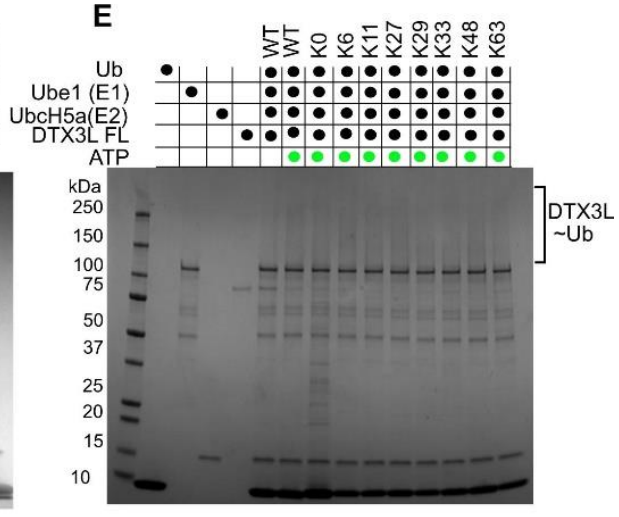

D

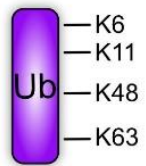

Fig 5. DTX3L undergoes multi-domain auto-ubiquitination. A) Time course analysis of autoubiquitnation of full-length DTX3L. Smears indicate formation of DTX3L-Ub conjugates. B) Constructs containing the $\mathrm{RD}$ domain are able to perform ubiquitinating activity. C) 
Summary of identified ubiquitination sites in DTX3L D) Mass spectrometry identified ubiquitinated lysines. E) Auto ubiquitination of DTX3L with WT Ub and lysine mutant panel of Ub.

\section{Heteromerization with PARP9 enhances E3 ligase and ADP-ribosyl transferase activity}

In our earlier studies[19] we reported that the DTX3L-PARP9 complex mediates ADPribosylation of $\mathrm{Ub}$ on the $\mathrm{C}$-terminal residue $\mathrm{Gly}^{76}$. Using highly pure preparations with individual proteins, we found that ADP-ribosylation of $\mathrm{Ub} \mathrm{Gly}^{76}$ could be catalyzed by DTX3L alone (Fig. 6A, lane 3). Including PARP9 in the reaction, however, enhanced ADP-ribosylation of Ub by 2.6 fold (Fig. 6A, lane 4). The presence of PARP9 also promoted the E3 activity of DTX3L, as indicated by the increased Ub-T7 product formation. Mono-ubiquitination of histone H2A by DTX3L increased by $60 \%$ in presence of PARP9 (Fig 6A, lane 4). Increasing NAD+ concentration to $1 \mathrm{mM}$ inhibited ubiquitin conjugation as expected because ADP-ribosylation of Ub precludes conjugation to substrate as expected [19]. These data suggest that PARP9 contributes to both the ADP-ribosylation and Ub ligase functions of the heterodimer.

A 200 amino acid C-terminal fragment of DTX3L (aa 557-740) was shown by Chatrin et al. to ADP-ribosylate Ub in vitro [34]. We therefore compared the activities of the DTX3L fragment to that of full-length DTX3L and the DTX3L-PARP9 heterodimer (Fig. 6B). The DTX3L fragment lacks the epitope for detection by the DTX3L antibody used in these assays, but was detected using 6-His antibody. We found that the fragment displays Ub (ADPribosyl)transferase activity that is higher than that of the full-length DTX3L. Full-length DTX3L alone is inefficient in Ub ADP-ribosylation, but the activity of the DTX3L-PARP9 heterodimer is at the same level as for the isolated DTX3L C-terminal fragment suggesting that contacts between DTX3L and PARP9 enable the ADP-ribosylation activity of DTX3L. 
A

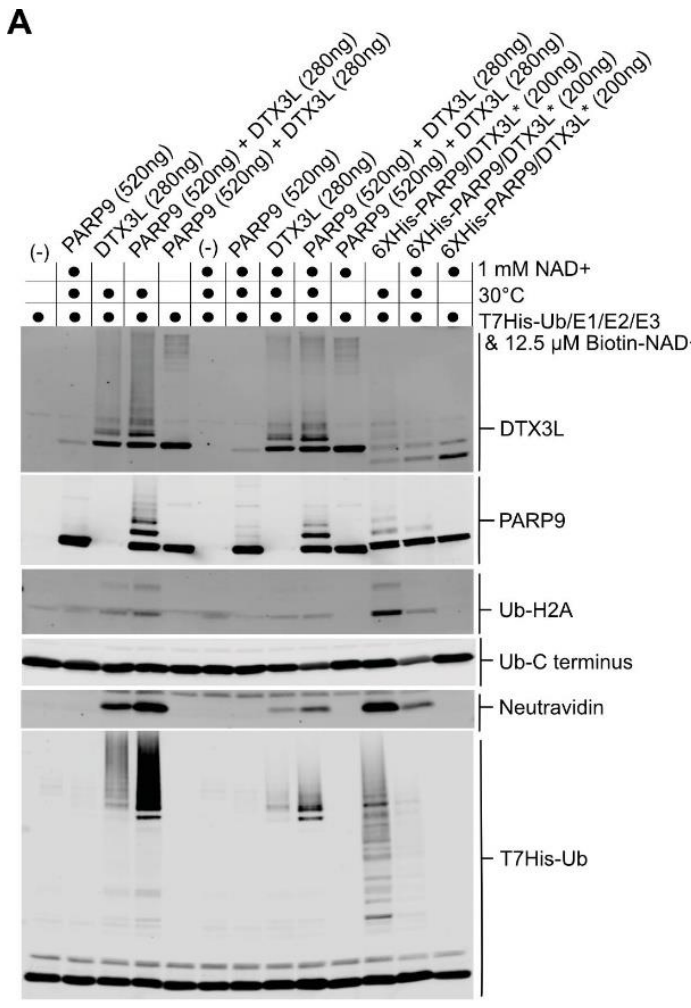

B

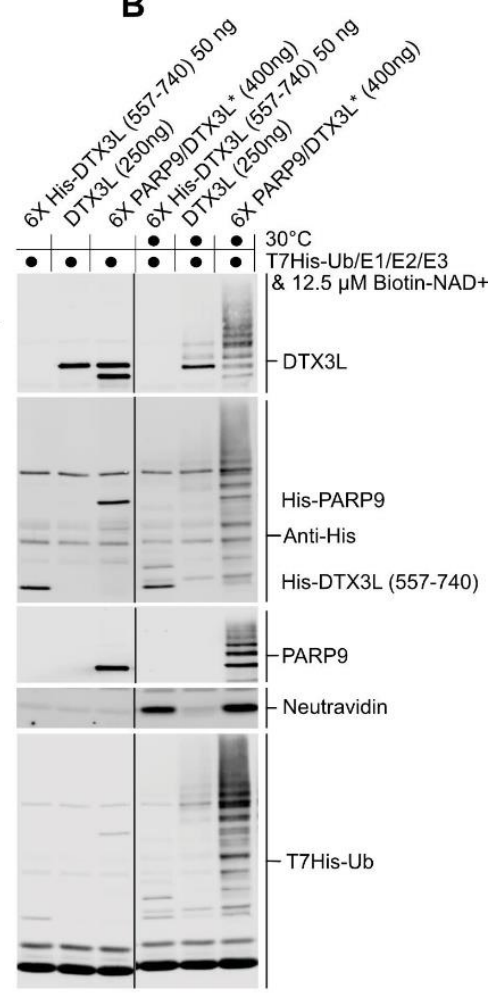

Fig 6. Heteromerization with PARP9 enhances DTX3L enzymatic activity. A) Assays with fulllength DTX3L and PARP9, individually and after heterodimer reconstitution. Protein components concentrations are indicated. All reactions contained E1, E2, histone H2A, T7His6-Ub, ATP, and Biotin-NAD+, and were incubated on ice or at $30^{\circ} \mathrm{C}$. A subset of reactions was supplemented with excess $\mathrm{NAD}^{+}(1 \mathrm{mM})$. The reaction products were analyzed by immunoblotting with the indicated antibodies. ADP-ribosylation of Ub was detected using fluorescently-labeled Neutravidin, as described [19]. *Indicates co-expressed heterodimer. B) Assays comparing the DTX3L Ring-DTX domain to full-length DTX3L and DTX3L-PARP9 heterooligomer. The reactions were performed and analyzed as described in Panel A. *Indicates co-expressed heterodimer.

\section{ADP-ribosylhydrolases catalyze the removal of ADP-ribose from Gly ${ }^{76} \mathrm{Ub}$}

During the completion of this study, it was reported that Ub Gly ${ }^{76}$ ADP-ribosylation can be reversed in vitro by deubiquitinases (DUBs) [34]. DUBs are not, however, the typical erasers of ADP-ribosylation and three families of ADP-ribosylation erasers have been reported, which 
is why we studied the possibility that hydrolases remove the modification. The erasers of ADPribosylation are grouped in the $\mathrm{ARH}$ family of enzymes (comprising $\mathrm{ARH} 1-3$ ), macrodomain containing enzymes (PARG, TARG1, MacroD1 and MacroD2), and nudix hydrolases. Apart from PARG, all erasers are dependent on the amino acid linkage to ADP-ribose. For example, ARH1 targets $\mathrm{N}$-glycosidic bonds on Arginine, whereas ARH3 targets O-glycosidic bonds on serine [35-37]. MacroD1, MacroD2 and TARG1 target ADP-ribose conjugated to acidic residues like glutamic acid and aspartic acid [38-41]. In contrast to other erasers, nudix are considered as partial hydrolases since they cleave the phosphodiester bond between adenosine and ribose instead of removing complete ADP-ribose units [42].
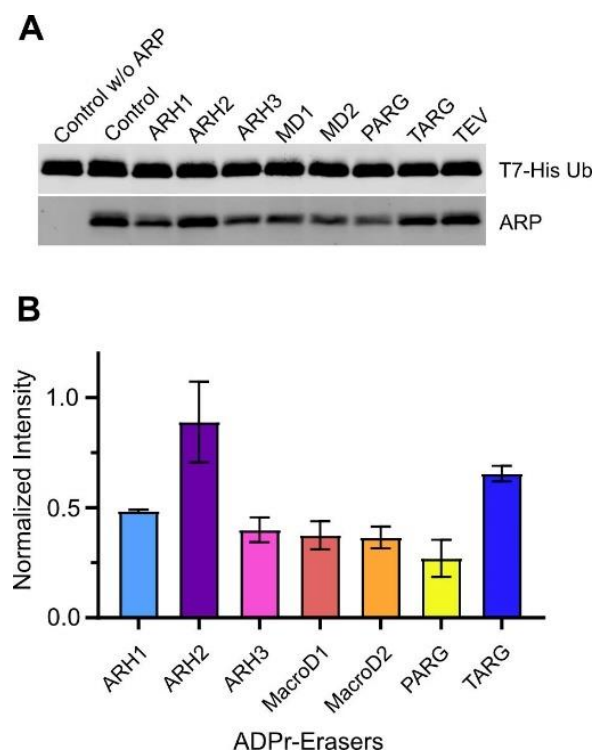

Fig 7. Several ADPr hydrolases can remove ADP-ribose from Gly ${ }^{76}$ Ub. A) Hydrolysis of ADPribose from the C-terminus of Ubiquitin by a panel of human (ADP-ribosyl)hydrolases. TEV protease was used as a control. $(n=2)$ D) Quantification of the hydrolysis activity from gel shown in A. Control Lane with ARP detection was normalized to 1.0.

We analyzed a panel of recombinant ADP-ribosylation erasers for the ability to remove the modification. Our results indicate that most of the enzymes tested can remove ADP-ribose from Ub- Gly ${ }^{76}$ (Fig. 7A,B). Both ARH1 and 3 had similar activities, but substrates for ARH2 
remain unknown and it did not show any activity towards Ub Gly ${ }^{76}$ ADPr. On the other hand, amongst enzymes that contain a macrodomain fold, PARG, MacroD1 and D2 showed high hydrolysis activities.

\section{Discussion}

DTX3L-PARP9 complex has both Ub E3 ligase and ADP-ribosylation activities. The significance of studies on this complex relies on its role in DNA damage repair pathways, cancer biology and in viral infection. For the first time, we have successfully purified full-length DTX3L and PARP9 and several truncation constructs. While DTX3L-PARP9 was shown to exist as a large complex in earlier studies, these studies used crude lysate to probe oligomeric status of the complex. In crude lysate preparations, other interacting proteins could modify solution behaviour of proteins. We show conclusively using pure preparations of PARP9 that it exists as a monomer in solution and DTX3L exists as a multimer. Studies with purified D1D2 domains showed that they mediate oligomerization in line with previous studies [20]. Further dissection of these domains separately into D1 and D2 indicated that majority of the oligomerization is driven by D2 domain with minor contributions from D1 domain. It must be noted that D1-D2 domains present a heterogeneous oligomer behaviour where the dominating species in solution seem to be either a pentamer or a hexamer as calculated from SAXS data. Multimerization is not an uncommon feature of E3 ligases, with well-characterised examples of homo-dimerization (such as RNF4, BIRC7, IDOL) as well as hetero-dimerization (including BRCA1-BARD1 and MDMX-MDM2) [33,43-46]. However, dimerization of those ligases is mainly mediated by the RING domain and with a clear effect on enzymatic activity [33,47-49]. Based on our results, RING domain of DTX3L is not involved in protein oligomerization.

We confirm earlier biochemical studies that D3 domain of DTX3L is sufficient for interaction with PARP9. D3 domain binds with nanomolar affinity to PARP9 which allows the formation of stable complexes in aSEC. Using XL-MS we have gained new information about the 
bioRxiv preprint doi: https//doi.org/10.1101/2021.06.14.448324; this version posted October 13,2021 . The copyright holder for this preprint (which was not certified by peer review) is the author/funder, who has granted bioRxiv a license to display the preprint in perpetuity. It is made available under aCC-BY-NC-ND 4.0 International license.

interaction at peptide level resolution. D3 domain makes contacts with linker region between M2 and catalytic domain of PARP9 and the catalytic domain. Intriguingly, crosslinks between two and K408 and K728 (DTX3L) residues could be identified while cross-linking full-length proteins implying that DTX domains from adjacent monomers come in close proximity in an oligomeric context.

Our results suggest that multimerization may act as a regulatory mechanism based on the MARylating activity towards $\mathrm{Ub}$, which can be a result of a rigid, unfavourable conformation for the full-length DTX3L enzyme as opposed to having a monomeric C-terminal fragment of the protein. Additionally, the identification of cross-linking regions between the catalytic domain suggests a more active participation from PARP9 in the reaction (Fig. 4). Interestingly, other interacting regions that were experimentally identified indicate a compact structure that brings to close proximity the R-DTX region of DTX3L to the macrodomains of PARP9. Taking this into account, it is possible that the compact structure of the complex facilitates the ubiquitination of PARylated proteins in the context of DNA damage. Our assumption is supported by the linkages identified by MS on ubiquitinated DTX3L, which are those relevant to the context of DDR, supporting previous findings [16].

ADP-ribosylation of $\mathrm{Ub}$ on Gly ${ }^{76}$ was initially reported in vitro and later shown to be present in cells [34]. However, no functions have been ascribed to this modification. It is hypothesized that conjugation of ADP-ribose on Gly $^{76}$ by DTX3L-PARP9 makes it unable to conjugate to proteins by the canonical pathway since the modification protects C-terminal glycine making it unavailable to ubiquitinate substrate proteins [21].

Earlier, one of our labs reported the existence of cellular factors that are capable of removing ADP-ribose from Ub Gly ${ }^{76}$ [19]. Based on previous studies, we assembled a panel of proteins known to remove ADP-ribose from proteins. We were able to identify some candidate proteins that can remove the ADPr moiety from ubiquitin in vitro. An interesting observation is that PARG is the most active of all studied proteins in removing ADPr from Ub. PARG is generally inefficient in breaking the ADPr-protein bond and much more efficient in hydrolyzing ADPr- 
ADPr bonds [50]. TARG on the other hand seemed inefficient by comparison despite being shown to be effective in acting upon protein-ADPr bonds [41,51]. Additionally, we observed that multiple enzymes efficiently remove ADPr from Ub-Gly ${ }^{76}$, including MacroD1, MacroD2, $\mathrm{ARH} 1$ and $\mathrm{ARH} 3$. All these are in vitro studies and the physiological relevance of these erasers would require further cell-based experiments.

In summary, we have used biochemical methods to characterize the DTX3L-PARP9 complex. DTX3L binds PARP9 with nanomolar affinity and relies on multiple inter-subunit contacts to help maintain the overall structure and biochemical activity of the complex. We provided evidence for intra-protein contacts within DTX3L, and also within PARP9. The latter included contacts both within and between the two macrodomains of PARP9, which are known to provide the complex with ADP-ribose reader function [52]. The coordinated expression and efficient assembly of DTX3L-PARP9 helps to bring together the E3, (ADP-ribosyl)transferase, and ADP-reader function into a single complex.

\section{Competing interests}

The authors declare that they have no competing interests.

\section{Funding}

The research was supported by the Academy of Finland grants 287063, 294085 and 319299 (to LL) and by an NIH grant No. R01CA214872 (to BMP), and by Leibniz Association with the Leibniz-Wettbewerbs (to FL).

\section{Data availability}

$\mathrm{XL}-\mathrm{MS}$ peptide analysis is available in the supplemental file. SAXS data is deposited to SASDB. 
bioRxiv preprint doi: https://doi.org/10.1101/2021.06.14.448324 this version posted October 13, 2021. The copyright holder for this preprint (which was not certified by peer review) is the author/funder, who has granted bioRxiv a license to display the preprint in perpetuity. It is made available under aCC-BY-NC-ND 4.0 International license.

\section{Author contributions}

LL and BMP conceived the research. YA, CVR and CY carried out biochemical experiments and analyzed the data. HIA carried out cloning and protein production. FL was responsible for the XL-MS measurements. YA, CVR, BMP and LL wrote the publication with contributions from all the authors.

\section{Acknowledgements}

We thank Kalle Niemi for testing ubiquitination reactions, Ulrich Bergman for expert help with ubiquitin site mapping, Hongmin Tu for expert help with BLI, Albert Galera-Prat for expert help with SAXS data analysis, and beam line scientists at Diamond Light Source B21 beamline for mail-in data collection service. The use of the facilities of the Biocenter Oulu Structural Biology core facility, member of Biocenter Finland, Instruct-ERIC Centre Finland and FINStruct, is gratefully acknowledged. We also thank the Biocenter Oulu Sequencing Center and Proteomics and protein analysis facility. We acknowledge Drs. Opher Gileadi, Cynthia Wolberger and Scott Gradia for making plasmids available through Addgene.

\section{References}

1 Swatek, K. N. and Komander, D. (2016) Ubiquitin modifications. Cell Research, Nature Publishing Group 26, 399-422.

2 Schichl, Y. M., Resch, U., Lemberger, C. E., Stichlberger, D. and de Martin, R. (2011) Novel Phosphorylation-dependent Ubiquitination of Tristetraprolin by Mitogen-activated Protein Kinase/Extracellular Signal-regulated Kinase Kinase Kinase 1 (MEKK1) and Tumor Necrosis Factor Receptor-associated Factor 2 (TRAF2). J Biol Chem 286, 38466-38477.

3 Vivelo, C. A., Ayyappan, V. and Leung, A. K. L. (2019) Poly(ADP-Ribose)-Dependent Ubiquitination and its Clinical Implications. Biochem Pharmacol 167, 3-12.

4 Lüscher, B., Ahel, I., Altmeyer, M., Ashworth, A., Bai, P., Chang, P., Cohen, M., Corda, D., Dantzer, F., Daugherty, M. D., et al. ADP-ribosyltransferases, an update on function and nomenclature. The FEBS Journal $\mathbf{n} / \mathbf{a}$.

5 Gatti, M., Imhof, R., Huang, Q., Baudis, M. and Altmeyer, M. (2020) The Ubiquitin Ligase TRIP12 Limits PARP1 Trapping and Constrains PARP Inhibitor Efficiency. Cell Reports 32, 107985.

6 Kang, H. C., Lee, Y.-I., Shin, J.-H., Andrabi, S. A., Chi, Z., Gagné, J.-P., Lee, Y., Ko, H. S., Lee, B. D., Poirier, G. G., et al. (2011) Iduna is a poly(ADP-ribose) (PAR)-dependent E3 ubiquitin ligase that regulates DNA damage. PNAS, National Academy of Sciences 108, 14103-14108. 
7 Dong, Y., Mu, Y., Xie, Y., Zhang, Y., Han, Y., Zhou, Y., Wang, W., Liu, Z., Wu, M. Wang, H., et al. (2018) Structural basis of ubiquitin modification by the Legionella effector SdeA. Nature, Nature Publishing Group 557, 674-678.

8 Kamata, T. and Paschal, B. (2018) ADP-Ribosylation of the Ubiquitin C-Terminus by Dtx3L/Parp9. Ubiquitin Proteasome System - Current Insights into Mechanism Cellular Regulation and Disease.

9 Kotewicz, K. M., Ramabhadran, V., Sjoblom, N., Vogel, J. P., Haenssler, E., Zhang, M., Behringer, J., Scheck, R. A. and Isberg, R. R. (2017) A single Legionella effector catalyzes a multi-step ubiquitination pathway to rearrange tubular endoplasmic reticulum for replication. Cell Host Microbe 21, 169-181.

10 Yan, F., Huang, C., Wang, X., Tan, J., Cheng, S., Wan, M., Wang, Z., Wang, S., Luo, S., $\mathrm{Li}$, A., et al. (2020) Threonine ADP-Ribosylation of Ubiquitin by a Bacterial Effector Family Blocks Host Ubiquitination. Molecular Cell 78, 641-652.e9.

11 Aguiar, R. C. T., Yakushijin, Y., Kharbanda, S., Salgia, R., Fletcher, J. A. and Shipp, M. A. (2000) BAL is a novel risk-related gene in diffuse large B-cell lymphomas that enhances cellular migration. Blood 96, 4328-4334.

12 Aguiar, R. C. T., Takeyama, K., He, C., Kreinbrink, K. and Shipp, M. A. (2005) Baggressive Lymphoma Family Proteins Have Unique Domains That Modulate Transcription and Exhibit Poly(ADP-ribose) Polymerase Activity. J. Biol. Chem. 280, 33756-33765.

13 Takeyama, K., Aguiar, R. C. T., Gu, L., He, C., Freeman, G. J., Kutok, J. L., Aster, J. C. and Shipp, M. A. (2003) The BAL-binding Protein BBAP and Related Deltex Family Members Exhibit Ubiquitin-Protein Isopeptide Ligase Activity *. Journal of Biological Chemistry, Elsevier 278, 21930-21937.

14 Obiero, J., Walker, J. R. and Dhe-Paganon, S. (2012) Fold of the conserved DTC domain in deltex proteins. Proteins: Structure, Function, and Bioinformatics 80, 14951499.

15 Juszczynski, P., Kutok, J. L., Li, C., Mitra, J., Aguiar, R. C. T. and Shipp, M. A. (2006) BAL1 and BBAP Are Regulated by a Gamma Interferon-Responsive Bidirectional Promoter and Are Overexpressed in Diffuse Large B-Cell Lymphomas with a Prominent Inflammatory Infiltrate. Molecular and Cellular Biology 26, 5348-5359.

16 Yan, Q., Xu, R., Zhu, L., Cheng, X., Wang, Z., Manis, J. and Shipp, M. A. (2013) BAL1 and Its Partner E3 Ligase, BBAP, Link Poly(ADP-Ribose) Activation, Ubiquitylation, and Double-Strand DNA Repair Independent of ATM, MDC1, and RNF8. Molecular and Cellular Biology 33, 845-857.

17 Camicia, R., Bachmann, S. B., Winkler, H. C., Beer, M., Tinguely, M., Haralambieva, E. and Hassa, P. O. (2013) BAL1/ARTD9 represses the anti-proliferative and pro-apoptotic IFNy-STAT1-IRF1-p53 axis in diffuse large B-cell lymphoma. Journal of Cell Science 126, 1969-1980.

18 Bachmann, S. B., Frommel, S. C., Camicia, R., Winkler, H. C., Santoro, R. and Hassa, P. O. (2014) DTX3L and ARTD9 inhibit IRF1 expression and mediate in cooperation with ARTD8 survival and proliferation of metastatic prostate cancer cells. Molecular Cancer 13, 125.

19 Yang, C.-S., Jividen, K., Spencer, A., Dworak, N., Ni, L., Oostdyk, L. T., Chatterjee, M., Kuśmider, B., Reon, B., Parlak, M., et al. (2017) Ubiquitin Modification by the E3 Ligase/ADP-Ribosyltransferase Dtx3L/Parp9. Molecular Cell 66, 503-516.e5.

20 Zhang, Y., Mao, D., Roswit, W. T., Jin, X., Patel, A. C., Patel, D. A., Agapov, E., Wang, Z., Tidwell, R. M., Atkinson, J. J., et al. (2015) PARP9-DTX3L ubiquitin ligase targets host histone $\mathrm{H} 2 \mathrm{BJ}$ and viral $3 \mathrm{C}$ protease to enhance interferon signaling and control viral infection. ni 16, 1215-1227.

21 Dye, B. T. and Schulman, B. A. (2007) Structural Mechanisms Underlying Posttranslational Modification by Ubiquitin-Like Proteins. Annu. Rev. Biophys. Biomol. Struct., Annual Reviews 36, 131-150.

22 Sowa, S. T., Vela-Rodríguez, C., Galera-Prat, A., Cázares-Olivera, M., PrunskaiteHyyryläinen, R., Ignatev, A. and Lehtiö, L. (2020) A FRET-based high-throughput 
screening platform for the discovery of chemical probes targeting the scaffolding functions of human tankyrases. Sci Rep 10, 12357.

23 van den Berg, S., Löfdahl, P.-A., Härd, T. and Berglund, H. (2006) Improved solubility of TEV protease by directed evolution. Journal of Biotechnology 121, 291-298.

24 Combe, C. W., Fischer, L. and Rappsilber, J. (2015) xiNET: cross-link network maps with residue resolution. Mol Cell Proteomics 14, 1137-1147.

25 Classen, S., Hura, G. L., Holton, J. M., Rambo, R. P., Rodic, I., McGuire, P. J., Dyer, K., Hammel, M., Meigs, G., Frankel, K. A., et al. (2013) Implementation and performance of SIBYLS: a dual endstation small-angle $X$-ray scattering and macromolecular crystallography beamline at the Advanced Light Source. J Appl Crystallogr 46, 1-13.

26 Petoukhov, M. V., Franke, D., Shkumatov, A. V., Tria, G., Kikhney, A. G., Gajda, M., Gorba, C., Mertens, H. D. T., Konarev, P. V. and Svergun, D. I. (2012) New developments in the ATSAS program package for small-angle scattering data analysis. $J$ Appl Crystallogr 45, 342-350.

27 Piiadov, V., Ares de Araújo, E., Oliveira Neto, M., Craievich, A. F. and Polikarpov, I. (2019) SAXSMoW 2.0: Online calculator of the molecular weight of proteins in dilute solution from experimental SAXS data measured on a relative scale. Protein Sci $\mathbf{2 8 ,}$ 454-463.

28 Rappsilber, J., Siniossoglou, S., Hurt, E. C. and Mann, M. (2000) A Generic Strategy To Analyze the Spatial Organization of Multi-Protein Complexes by Cross-Linking and Mass Spectrometry. Anal. Chem., American Chemical Society 72, 267-275.

$29 \mathrm{Yu}, \mathrm{C}$. and Huang, L. (2018) Cross-Linking Mass Spectrometry (XL-MS): an Emerging Technology for Interactomics and Structural Biology. Anal Chem 90, 144-165.

30 Lu, C.-S., Truong, L. N., Aslanian, A., Shi, L. Z., Li, Y., Hwang, P. Y.-H., Koh, K. H., Hunter, T., Yates, J. R., Berns, M. W., et al. (2012) The RING finger protein RNF8 ubiquitinates Nbs1 to promote DNA double-strand break repair by homologous recombination. J Biol Chem 287, 43984-43994.

31 Morris, J. R. and Solomon, E. (2004) BRCA1 : BARD1 induces the formation of conjugated ubiquitin structures, dependent on $\mathrm{K} 6$ of ubiquitin, in cells during DNA replication and repair. Hum Mol Genet 13, 807-817.

32 Paul, A. and Wang, B. (2017) RNF8- and Ube2S-Dependent Ubiquitin Lysine 11Linkage Modification in Response to DNA Damage. Mol Cell 66, 458-472.e5.

33 Wu-Baer, F., Lagrazon, K., Yuan, W. and Baer, R. (2003) The BRCA1/BARD1 Heterodimer Assembles Polyubiquitin Chains through an Unconventional Linkage Involving Lysine Residue K6 of Ubiquitin*. Journal of Biological Chemistry 278, 3474334746.

34 Chatrin, C., Gabrielsen, M., Buetow, L., Nakasone, M. A., Ahmed, S. F., Sumpton, D., Sibbet, G. J., Smith, B. O. and Huang, D. T. (2020) Structural insights into ADPribosylation of ubiquitin by Deltex family E3 ubiquitin ligases. Science Advances, American Association for the Advancement of Science 6, eabc0418.

35 Abplanalp, J., Leutert, M., Frugier, E., Nowak, K., Feurer, R., Kato, J., Kistemaker, H. V. A., Filippov, D. V., Moss, J., Caflisch, A., et al. (2017) Proteomic analyses identify ARH3 as a serine mono-ADP-ribosylhydrolase. Nat Commun 8, 2055.

36 Fontana, P., Bonfiglio, J. J., Palazzo, L., Bartlett, E., Matic, I. and Ahel, I. (2017) Serine ADP-ribosylation reversal by the hydrolase ARH3. Elife 6.

37 Kato, J., Zhu, J., Liu, C. and Moss, J. (2007) Enhanced Sensitivity to Cholera Toxin in ADP-Ribosylarginine Hydrolase-Deficient Mice. Mol Cell Biol 27, 5534-5543.

38 Chen, D., Vollmar, M., Rossi, M. N., Phillips, C., Kraehenbuehl, R., Slade, D., Mehrotra, P. V., von Delft, F., Crosthwaite, S. K., Gileadi, O., et al. (2011) Identification of macrodomain proteins as novel O-acetyl-ADP-ribose deacetylases. J Biol Chem 286, 13261-13271.

39 Jankevicius, G., Hassler, M., Golia, B., Rybin, V., Zacharias, M., Timinszky, G. and Ladurner, A. G. (2013) A family of macrodomain proteins reverses cellular mono-ADPribosylation. Nat Struct Mol Biol 20, 508-514. 
40 Rosenthal, F., Feijs, K. L. H., Frugier, E., Bonalli, M., Forst, A. H., Imhof, R., Winkler, H. C., Fischer, D., Caflisch, A., Hassa, P. O., et al. (2013) Macrodomain-containing proteins are new mono-ADP-ribosylhydrolases. Nat Struct Mol Biol 20, 502-507.

41 Sharifi, R., Morra, R., Appel, C. D., Tallis, M., Chioza, B., Jankevicius, G., Simpson, M. A., Matic, I., Ozkan, E., Golia, B., et al. (2013) Deficiency of terminal ADP-ribose protein glycohydrolase TARG1/C6orf130 in neurodegenerative disease. EMBO J 32, 12251237.

42 O'Sullivan, J., Tedim Ferreira, M., Gagné, J.-P., Sharma, A. K., Hendzel, M. J., Masson, J.-Y. and Poirier, G. G. (2019) Emerging roles of eraser enzymes in the dynamic control of protein ADP-ribosylation. Nat Commun 10.

43 Liew, C. W., Sun, H., Hunter, T. and Day, C. L. (2010) RING DOMAIN DIMERIZATION IS ESSENTIAL FOR RNF4 FUNCTION. Biochem J 431, 23-29.

44 Dou, H., Buetow, L., Sibbet, G. J., Cameron, K. and Huang, D. T. (2012) Structure of BIRC7-E2 ubiquitin conjugate reveals the mechanism of ubiquitin transfer by a RING dimer. Nat Struct Mol Biol 19, 10.1038/nsmb.2379.

45 Zhang, L., Fairall, L., Goult, B. T., Calkin, A. C., Hong, C., Millard, C. J., Tontonoz, P. and Schwabe, J. W. R. (2011) The IDOL-UBE2D complex mediates sterol-dependent degradation of the LDL receptor. Genes Dev 25, 1262-1274.

46 Linke, K., Mace, P. D., Smith, C. A., Vaux, D. L., Silke, J. and Day, C. L. (2008) Structure of the MDM2/MDMX RING domain heterodimer reveals dimerization is required for their ubiquitylation in trans. Cell Death Differ 15, 841-848.

47 Mace, P. D., Linke, K., Feltham, R., Schumacher, F.-R., Smith, C. A., Vaux, D. L., Silke, J. and Day, C. L. (2008) Structures of the cIAP2 RING Domain Reveal Conformational Changes Associated with Ubiquitin-conjugating Enzyme (E2) Recruitment*. Journal of Biological Chemistry 283, 31633-31640.

48 Yin, Q., Lin, S.-C., Lamothe, B., Lu, M., Lo, Y.-C., Hura, G., Zheng, L., Rich, R. L., Campos, A. D., Myszka, D. G., et al. (2009) E2 interaction and dimerization in the crystal structure of TRAF6. Nat Struct Mol Biol 16, 658-666.

49 Plechanovová, A., Jaffray, E. G., McMahon, S. A., Johnson, K. A., Navrátilová, I., Naismith, J. H. and Hay, R. T. (2011) Mechanism of ubiquitylation by dimeric RING ligase RNF4. Nat Struct Mol Biol 18, 1052-1059.

50 Slade, D., Dunstan, M. S., Barkauskaite, E., Weston, R., Lafite, P., Dixon, N., Ahel, M., Leys, D. and Ahel, I. (2011) The structure and catalytic mechanism of a poly(ADPribose) glycohydrolase. Nature 477, 616-620.

51 Peterson, F. C., Chen, D., Lytle, B. L., Rossi, M. N., Ahel, I., Denu, J. M. and Volkman, B. F. (2011) Orphan Macrodomain Protein (Human C6orf130) Is an O-Acyl-ADP-ribose Deacylase. J Biol Chem 286, 35955-35965.

52 Kamata, T., Yang, C.-S., Melhuish, T. A., Frierson, H. F., Wotton, D. and Paschal, B. M. (2021) Post-Transcriptional Regulation of PARP7 Protein Stability Is Controlled by Androgen Signaling. Cells 10. 